\title{
Efficient Markets Hypothesis in the Time of COVID-19
}

\author{
VASILEIOU EVANGELOS \\ University of the Aegean School of Engineering, \\ Department of Financial and Management Engineering*
}

\begin{abstract}
This paper examines how the largest stock market of the world, the U.S., and particularly the S\&P500 index, reacted during the COVID-19 outbreak (02.01.2020-30.04.2020). Using simple financial analysis procedures for our theoretical framework, we juxtapose the released news with the respective market performance in order to examine if the stock market always incorporated the available information in time. We show that the market in some sub-periods was not moving as it was expected, and the runs-test statistically confirmed our assumptions that the US stock market was not always efficient during the COVID-19 outbreak. The market's behavior is unpredictable for a rational asset pricing model because as this paper shows even the simplest financial theories could explain rational behavior, but the market presented a different performance.
\end{abstract}

Keywords: Efficient Market Hypothesis; Rationality; Runs-test; Predictable Behavior; COVID-19; Health Risk

JEL Classifications: G12; G14; G32; G40; I1

\section{Introduction}

On 31 December 2019, the World Health Organization (WHO) China Country Office was informed of cases of pneumonia of unknown etiology (unknown cause) detected in Wuhan City, Hubei Province of China. The Chinese authorities identified a new type of coronavirus, which was isolated on 7 January 2020. The WHO named the novel coronavirus, Severe Acute Respiratory Syndrome Coronavirus 2 (SARS-CoV-2), and the disease coronavirus disease (COVID-19) ${ }^{1}$. On 30 January, WHO declared the outbreak a Public Health Emergency of International Concern (PHEIC) ${ }^{2}$, and on 11 March, WHO Director General characterized COVID-19 as a pandemic ${ }^{3}$.

\footnotetext{
(C) 2021 Vasileiou Evangelos. Licensed under the Creative Commons Attribution - Noncommercial 4.0 License (http://creativecommons.org/licenses/by-nc/4.0/. Available at http://rofea.org.

${ }^{1}$ Some highlights from the Novel Coronavirus $(2019-\mathrm{nCoV})$ SITUATION REPORT - 1 (World Health Organization): https://www.who.int/docs/default-source/coronaviruse/situation-reports/20200121-sitrep-12019-ncov.pdf

${ }^{2}$ The term Public Health Emergency of International Concern is defined in the International Health Regulations as "an extraordinary event which is determined, as provided in these Regulations: (i) to constitute a public health risk to other States through the international spread of disease; and (ii) to potentially require a coordinated international response". This definition implies a situation that: is serious, unusual or unexpected; carries implications for public health beyond the affected State's national border; and may require immediate international action. (source: https://www.who.int/ihr/procedures/pheic/en/)

${ }^{3}$ https://www.who.int/westernpacific/emergencies/covid-19
} 
This brief timeline of the COVID-19 outbreak shows that since 30 January 2020 (at least) the health risk worldwide due to COVID-19 has significantly increased. Was the U.S. stock market, the largest stock market of the world, efficient and rational during the first months of the COVID-19 outbreak? We use the widely accepted S\&P500 as a market index, and the sample period we examine is the 02.01.2020-30.04.2020

The COVID-19 outbreak gives us the opportunity to examine the Efficient Market Hypothesis $(\mathrm{EMH})$ in an extreme stress period, and to suggest some new factors that should be included in the EMH study, such as the promptness and the rationality of the stock markets. According to Fama (1970) and his seminal paper for the Efficient Market Hypothesis (EMH):

- "... the theory of efficient markets is concerned with whether prices at any point in time "fully reflect" available information."

- "Strong-form tests are concerned with whether individual investors or groups have monopolistic access to any information relevant for price formation."

- “...semi-strong-form tests the information subset of interest includes all obviously publicly available information, while in the weak form tests the information subset is just historical price or return sequences".

- Did the stock index incorporate all the available information at any point in time? The information we mention in this study is the publicly available information regarding the COVID19 outbreak. Any investor, individual or not, could have had access to the public information regarding COVID-19. We present how a price evaluation technique should work in theory based on fundamental financial analysis. This approach is easy to explain and understand, therefore, we can show that in some periods even though the stock prices should have a specific performance (growth/recession) the empirical evidence shows a different direction.

Using simple statistical techniques and econometric procedures, we show that the largest stock market of the world was not efficient during the examined period. In some periods, the market's response is slow and not consistent with the financial theory. These results show that something is missing from asset pricing models, and COVID-19 gives financial economists a chance to examine why investors underestimated the health risk, making the stock market inefficient.

A very interesting interview of Nobel laureates E. Fama and R. Thaler where they discuss predictability and market behavior prompted us to study the behavior of the US stock market during this outbreak. Even though the two distinguished professors adopt different approaches in finance, and in many cases disagree, at some point in their discussion they agree on the following: the market's behavior is not always predictable for a rational model ${ }^{4}$. Thus, the purpose of this study is to theoretically and quantitatively show the inefficiency and the irrationality of the market, and to raise some questions as to whether terms such as predictable behavior should be included in the EMH discussion.

\footnotetext{
${ }^{4}$ The interview is available on https://www.youtube.com/watch? $\mathrm{v}=\mathrm{bM} 9 \mathrm{bYOBuKF} 4 \& \mathrm{t}=1879 \mathrm{~s}$, and the part we mentioned is on 28:39-28:53.
} 


\section{EVANGELOS Efficient Markets Hypothesis and COVID-19}

The rest of the paper goes as following: Section 2 presents the theoretical framework regarding how the health risk due to COVID-19 should influence the stock market and Section 3 presents a basic financial analysis framework for the process of evaluating stock prices. Section 4 provides empirical evidence of the S\&P 500 index performance during the COVID-19 outbreak and analyses the outcomes. Section 5 uses the runs test in order to econometrically and quantitatively examine the efficiency of the U.S. stock market during the examined period, and Section 6 concludes the study.

\section{Health Risk, Economic Activity and Financial Markets: A Theoretical Framework}

A question which emerges is: should a pandemic influence an economy and its stock market? The reply is "yes". A pandemic affects a large number of people and causes widespread devastation. Many people get sick, the death toll rises and the healthcare system struggles to cope with a surge in hospitalizations. In order to contain the spread of the virus, social distancing measures and lockdowns are implemented, which causes the economic activity to slow down (Almond, \& Mazumder (2005), Garret (2008), and Keogh-Brown, Wren-Lewis, Edmunds, Beutels, \& Smith (2010)). As a consequence, a lot of businesses reduce their production, unemployment figures skyrocket and consumption is reduced due to income shrinkage. This means that companies have reduced profits, the growth expectations are revised negatively and so forth.

Moreover, a behavioral explanation is that the health risk turns to economic and financial risk because the investors' risk aversion increases when an economic crisis emerges (Cohn et al. (2015), Malmendier and Nagel (2011)), and/or when the health risk increases (Decker and Schmitz (2016)) Therefore, the increased health risk due to COVID-19, should increase risk aversion, and the economic slowdown/crisis caused by the pandemic should further increase risk aversion, thus the stock market should be under crisis. Al-Awadhi, Al-Saifi, Al-Awadhi and Alhamadi (2020) provide empirical evidence for the negative influence of COVID-19 on the Chinese stock market performance, and confirm the previously mentioned financial theories.

\section{A Financial Analysis Framework}

In financial markets, two of the most important measures for financial decisions are the expected rate of return $(\hat{r})$, and the expected standard deviation $(\sigma)$. Based on these measures, we examine the process of an investor's financial evaluation, using Figure 1(a). An investor may take into consideration $n$ possible scenarios. Each scenario has a probability i, where $i=1,2, \ldots$, to be confirmed, and for each scenario there is the respective expected outcome based on an asset pricing model.

If we assume that there is an asset pricing model that accurately estimates the expected return per case when the financial conditions are described, the crucial parameter is the probability for each Scenario to play out in the real world. The expected rate and the standard deviation are estimated using the following formulas:

5 ... and an upcoming pandemic increases the health risk. 
Review of Economic Analysis 13 (2021) 45-62

$$
\text { Expected Rate of Return }=\hat{r}=\sum_{i=1}^{n} P_{i} \times r_{i}
$$

where $\mathrm{P}_{\mathrm{i}}=$ the probability of occurrence of some financial conditions that lead to a respective return $\mathrm{r}_{\mathrm{i}}$, $\mathrm{i}=$ the event/scenario $1,2, \ldots, \mathrm{n}$, and

$$
\text { Standard Deviation }=\sigma=\sqrt{\left(r_{i}-\hat{r}\right)^{2} \times P_{i}}
$$

We assume that initially we are in late December 2019 (or even in early January 2020), and we make our investment plans for 2020: Scenario 1 is the best-case scenario, Scenario 2 the second best, ..., and Scenario $n$ is the worst. Every investor has her/his own scenarios under specific possibilities and her/his own estimations regarding each scenario's outcome. The stock market's performance is configured by the cumulative estimations of the investors. When the investors that include more positive scenarios-we call them for the purpose of this paper optimistic-are more than the investors that adopt moderate and/or negative scenarios, the stock market will go up and vice versa. The greater the disagreements of the market participants/investors regarding the values of stock prices, the higher the stock market's standard deviation will be.

For the COVID-19 case, when the news regarding the clustered cases of pneumonia in Wuhan was released, was a pandemic scenario included in the evaluation process? If the pandemic scenario was not in the evaluation process, the expected return is overestimated, and the expected risk is underestimated because a negative scenario has not been taken into consideration (equations (1) and (2)). Up to the first days of January, the news was not so worrying, and therefore the absence of the pandemic scenario may not be so irrational.

However, the financial markets are not static. The scenarios dynamically change as new information comes to light. As the news regarding the COVID-19 outbreak is released, the probability of a pandemic should:

- be taken into consideration, if the $\mathrm{n}$ scenarios of Figure 1(a) did not include a pandemic scenario, and

- increase, if one of the $n$ scenarios of Figure 1(a) included a pandemic scenario which was possible, but not highly probable.

For any individual investor/portfolio manager this means that the revised expected returns should be lower, and the standard deviation higher, when the pandemic scenario is close to confirmation. All these differences should be depicted in market performance: lower return estimations and increased standard deviations.

In Figure 1(b), we assume that we are on the day of the PHEIC announcement, the stock market has the information for a very bad scenario regarding the COVID-19 spread around the globe, and therefore it theoretically should decline. Depending on the other m-scenarios, e.g. the investors' expectations regarding the pandemic influence on the U.S. stock market, the expectations regarding government response to the COVID-19 outbreak (protective measures against the virus spread, economic relief 
Figure 1: The Expected Return and Standard Deviation Scenarios during the COVID-19 Outbreak (a) The Expected Return and Standard Deviation Before the Release of the News Regarding COVID-19

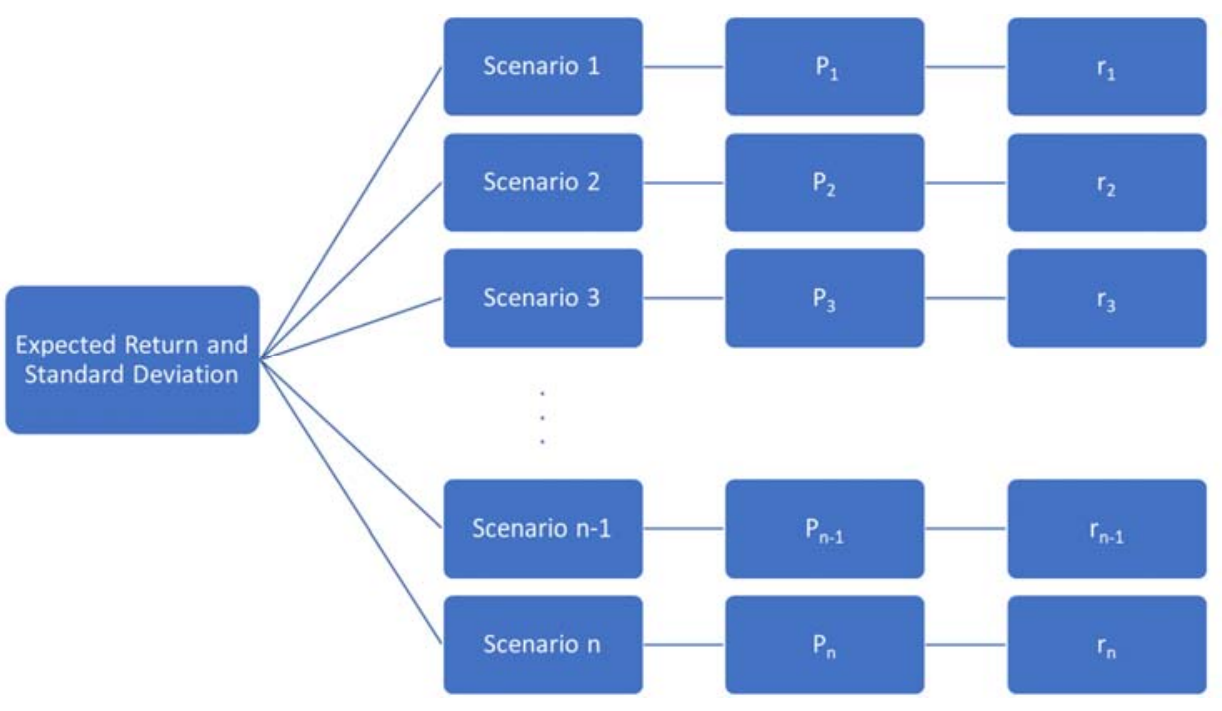

(b) The Expected Return and Standard Deviation when the News Shows that COVID-19 Turns to a PHEIC/Pandemic

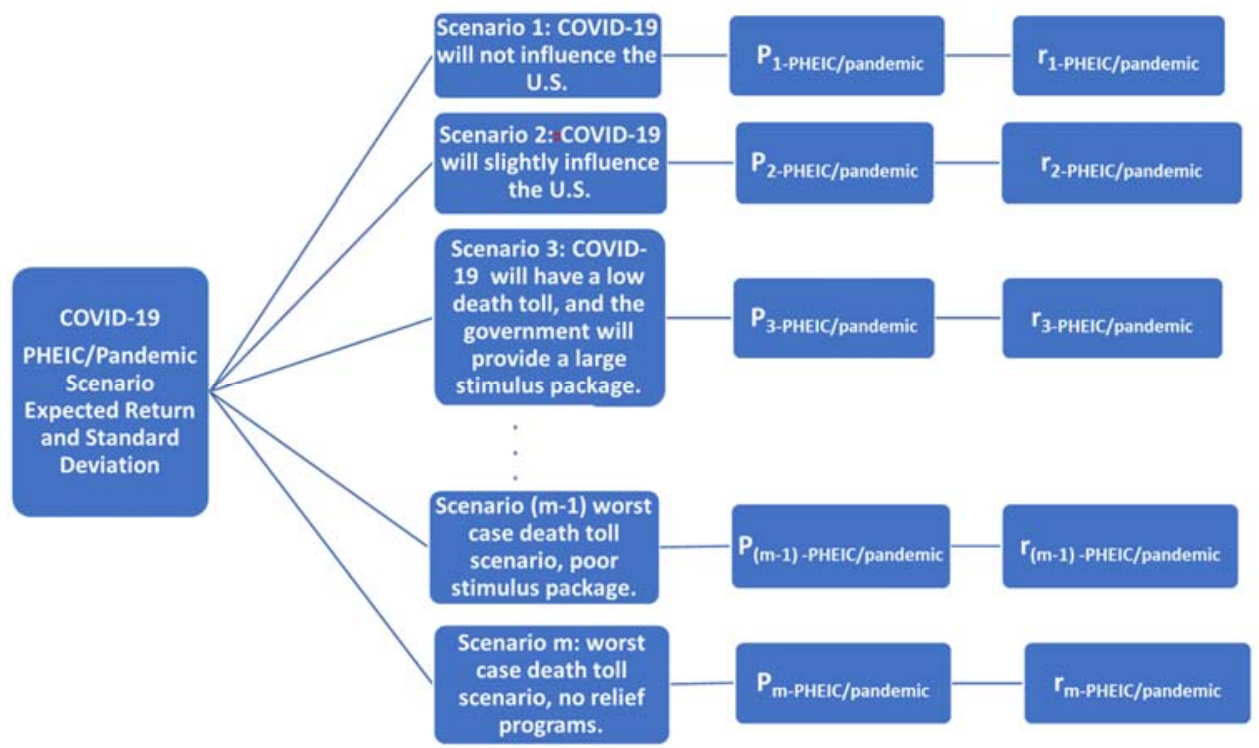


measures against a recession) etc., new estimations regarding the expected return and standard deviations of the asset prices will be estimated. Similar procedures will be followed when the pandemic is declared.

If the stock market evaluates the new information as positive (negative) the stock market prices should increase (decrease). In Figure 1(b), we have described some indicative sub-scenarios so as to show how this procedure creates multiple different sub-scenarios, which closely approximate possible real-life events, based on one initial scenario.

Depending on the scenarios, their possibility to occur, and the estimations of each scenario's outcome, each investor draws his/her strategy, and all the investors together shape the market's performance. This procedure is dynamic, and depending on the news, all these parameters are constantly revised.

\section{S\&P 500 index performance during the COVID-19 outbreak.}

Using data from the S\&P 500, we examine how the most popular investment index of the U.S. stock market reacted during the COVID-19 outbreak. We separate our data in three basic sub-periods which are based on the WHO reports ${ }^{6}$ :

I. 1st period: 02.01.2020 - 29.01.2020: first notice by the Chinese authorities up to the day before the PHEIC declaration

II. 2nd period: 30.01.2020-10.03.2020: after the PHEIC declaration up to the day before the pandemic declaration

III. 3th period: 11.03.2020-30.04.2020: the post-pandemic declaration period.

Figure 2 presents the cumulative returns from the beginning of the year to 30 April, 2020 the timeline of the abovementioned dates, and the respective performance of the market. Table 1 presents the cumulative returns per period and the respective standard deviation, adopting the following formulas:

- the daily returns, which are estimated by the formula

$$
\text { Daily Returns }_{\mathrm{t}}=r_{t}=\frac{\mathrm{S} \& P 500 \text { Price }_{\mathrm{t}}}{\mathrm{S \& P} 500 \text { Price }_{\mathrm{t}-1}}-1
$$

when $t$ is the $S \& P 500$ Price on day $t$ and $t-1$ is the $S \& P 500$ Price in the previous date,

- the cumulative returns, which are estimated by the formulae

$$
\text { Cumulative Returns per period }=\left[\prod_{i=1}^{N}\left(1+r_{i}\right)\right]-1
$$

where $r_{i}=$ the daily return of the stock index in day $i$, and $i=1,2, \ldots, N$ the first day of the period up to the last one, and

\footnotetext{
${ }^{6}$ WHO reports were publicly available to all investors; therefore, the news should be incorporated in the stock prices.
} 
EVANGELOS Efficient Markets Hypothesis and COVID-19

Figure 2: S\&P 500 the Cumulative Returns 02.01.2020-30.04.2020.

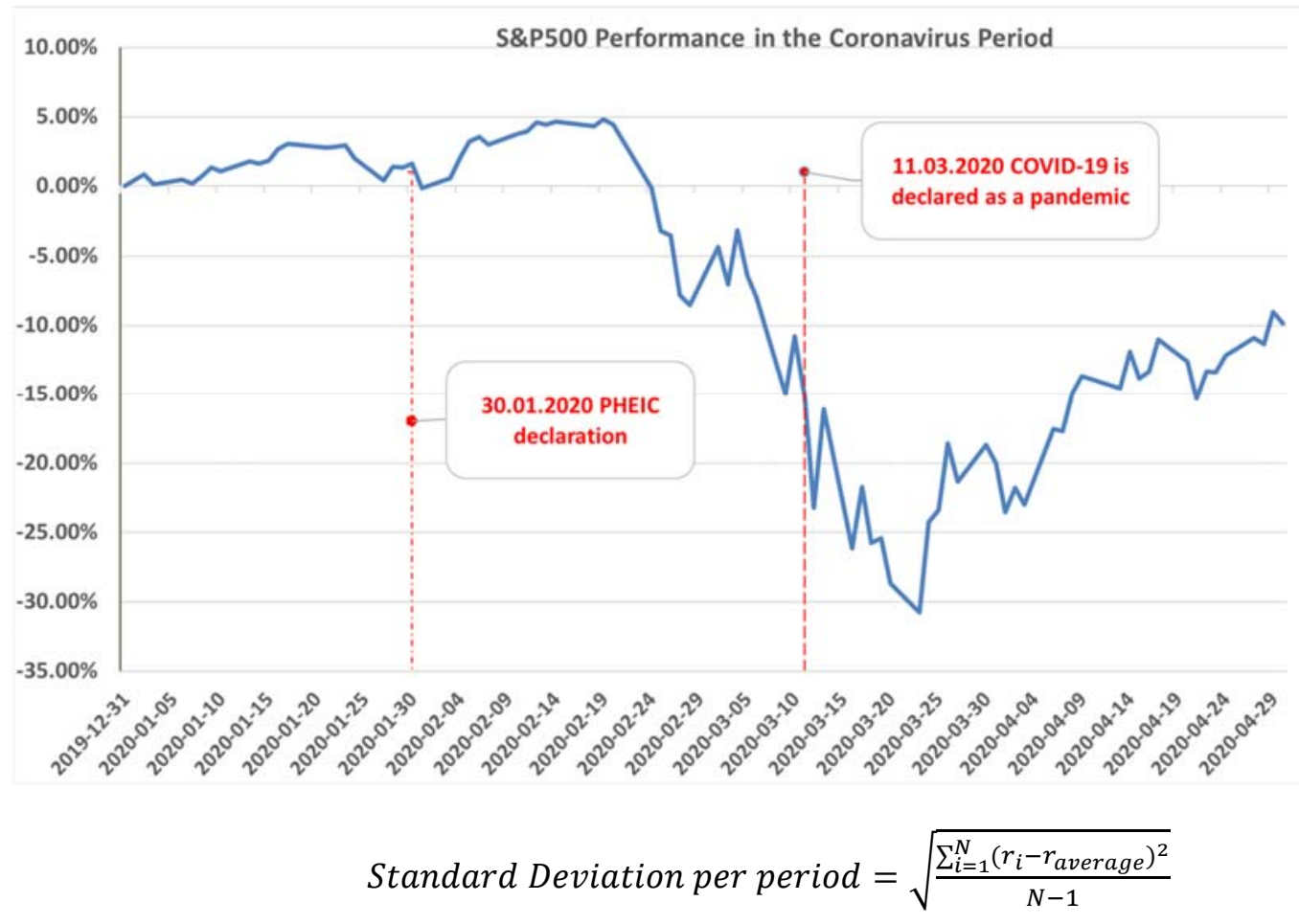

where $r_{\text {average }}=$ the mean return during the examined period.

We examine the performance of the stock market during the respective periods in order to draw some conclusions regarding the market's rationality and efficiency. The explanation of the market's responses to the news during the COVID-19 outbreak is based on the following assumptions:

- when the return seems irrational it could be a false estimation of a period, but when the standard deviation of this period is low this means either that there is no new information that could significantly influence the prices or that most participants in the market agree that the prices are fair,

- when the stock market presents increased standard deviation, it may be an indication for:

$\circ$ increased news of different directions (positive, and negative), and/or

○ counterarguments regarding the stock market's fair value, and/or

○ investors' overreaction which is aptly described by De Bondt and Thaler (1985): "In revising their beliefs, individuals tend to overweight recent information and underweight prior (or base rate) data."”.

${ }^{7}$ This adequately explains what happens during increased volatility periods, when significant news is brought to light. 
- when the risk (standard deviation) regarding the economic conditions in the U.S. is increased, an individual investor will try either to find alternative investments to the U.S. stock market, or (s)he will ask for increased required rate of return. In both cases, the stock market should fall. In finance, the negative relationship between risk and return is described by the leverage effect, which is the tendency of the stock prices to present higher volatility during large price falls than the respective volatility during growth periods.

Below we present the data during the examined sub-periods.

\section{(a) The 02.01.2020-29.01.2020 period.}

During the first period, the results show that the stock market presents a performance similar to that of a normal/growth period ${ }^{8}: 1.32 \%$ return, and $0.66 \%$ standard deviation. The results, and especially the low standard deviation, show that the stock market probably underestimated the COVID-19 risk, e.g. investors assumed that COVID-19 could be contained in China. Supporters of the EMH could argue that up to the PHEIC declaration the news regarding the spread of COVID-19 was not so worrying and hence the normal performance measures are rational and efficient.

However, how rational is the argument that in a globalized financial environment COVID-19 would not travel to the U.S.? We present some thoughts: before the COVID-19 outbreak there were more than 160 thousand flights per day, and for many of them the final destination was the U.S. ${ }^{9}$. On 2 February, 2020 restrictions on travel from China came into effect in the U.S. ${ }^{10}$; however, estimations show that up to this date hundreds of thousands of people have already travelled directly from China to the U.S. ${ }^{11}$, and probably many other passengers have travelled to the U.S. from other countries where cases of COVID-19 had already been documented. Therefore, the authorities and markets should have strongly suspected that COVID-19 has travelled from China (and/or indirectly from any other place of the world, e.g. Europe ${ }^{12}$ ), and there could potentially be cases of COVID-19 in any state.

Up to this period, there are no strict measures (lockdowns, social distance measures etc.) in the U.S.. Was it rational to assume that a highly contagious virus would not spread to the U.S. where $82.46 \%$ of the population lives in urban areas ${ }^{13}$ ? Social distance measures which were adopted to limit the spread

\footnotetext{
${ }^{8}$ For example, in 2019 the S\&P500 presented a $28.88 \%$ growth $(2.41 \%$ on average per month) and $0.79 \%$ daily standard deviation.

${ }^{9}$ https://www.flightradar24.com/

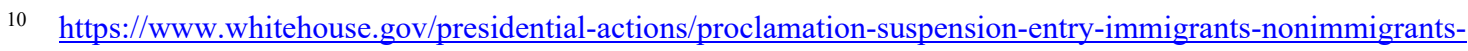
persons-pose-risk-transmitting-2019-novel-coronavirus/

${ }^{11}$ https://www.nytimes.com/2020/04/04/us/coronavirus-china-travel-restrictions.html

12 https://www.bloomberg.com/news/articles/2020-04-08/most-nyc-covid-19-cases-came-from-europe-genomeresearchers-say

${ }^{13}$ https://data.worldbank.org/indicator/SP.URB.TOTL.IN.ZS?locations=US
} 
of the virus require at least 1-meter ( 3 feet) distance ${ }^{14}$. During normal periods in urban settings do people keep such a distance between each other, e.g. in buses, trains, airports, schools etc.? Usually, no. Therefore, there were many possibilities that the virus was not only present in the U.S., but there was also a good possibility that it was already spreading within the U.S.. Additionally, people 65 years and older are at higher risk for severe illness and complications from the disease, which means that the death toll might be significantly high in a country where $16.21 \%$ of the population is over 65 years old ${ }^{15}$.

Moreover, during this period the Centers for Disease Control and Prevention (CDC) reports the first COVID-19 case on 19 January, and a second one on 24 January ${ }^{16}$. Even if there was no scenario of wide spread of COVID-19 in the U.S. stock market, this piece of news should create one because the first COVID-19 cases are proof that the disease has travelled to the U.S., and in theory, this should lead to market decline, and/or increased volatility.

In order to examine in theory if the stock market adequately evaluated the aforementioned thoughts and facts, we ask the following question: if the stock market during this period presented a lower return, and increased standard deviation, would these performance measures be irrational? If the reply is negative, the real stock market prices do not include all the available information.

Moreover, using the theoretical framework and the n-possible scenarios we presented in Section 3, was it rational not to have taken into consideration any scenario where COVID-19 could spread outside China and/or that could have travelled in the U.S.? If these scenarios were not considered during this period, then the stock market significantly have underestimated the health risk that COVID-19 poses. Perhaps, the stock market participants believed that SARS-Cov-2 would be contained in the same way SARS-Cov-1 and MERS were, two viruses which ended up having a relatively small effect on the economy, but as we presented above with 160 thousand flights per day, a highly contagious virus could travel worldwide in a few days.

\section{(b) The 30.01.2020-10.03.2020 period.}

In Table 1, the results show that the market is efficient when we examine the market performance from the beginning to the end of the period: cumulative returns show an $11.95 \%$ decline and an increased standard deviation to $2.65 \%$. This is an indication that the stock market evaluated the increased health risk after the PHEIC announcement. However, the data show that the response was not instant as the EMH suggests.

For the 30.01.2020-21.02.2020 period the performance measures are: $1.97 \%$ returns, $0.82 \%$ daily standard deviation. If we only focus on these performance measures, could we understand that something worrying as the PHEIC was announced? Possibly the reply would be negative. These results show that the stock market keeps underestimating the virus spread for many days after the PHEIC.

\footnotetext{
${ }^{14}$ https://www.who.int/emergencies/diseases/novel-coronavirus-2019/advice-for-public

${ }^{15} \mathrm{https}$ ://data.worldbank.org/indicator/SP.POP.65UP.TO.ZS?end=2018\&locations $=$ US\&start=2018\&view=map

${ }^{16} \mathrm{We}$ used information from https://www.brookings.edu/research/the-federal-governments-coronavirus-actionsand-failures-timeline-and-themes/ to timeline the facts.
} 
Review of Economic Analysis 13 (2021) 45-62

Table 1: The S\&P 500 Performance During the COVID-19 Outbreak.

\begin{tabular}{|l||c|c|c|c|}
\hline \multirow{2}{*}{ Period } & $02.01 .2020-$ & $02.01 .2020-$ & $30.01 .2020-$ & $11.03 .2020-$ \\
& 30.04 .2020 & 29.01 .2020 & 10.03 .2020 & 30.04 .2020 \\
\hline \hline Cumulative Returns & $-9.85 \%$ & $1.32 \%$ & $-11.95 \%$ & $1.05 \%$ \\
\hline Standard Deviation & $3.37 \%$ & $0.66 \%$ & $2.65 \%$ & $4.57 \%$ \\
\hline
\end{tabular}

The negative scenarios regarding the COVID-19 outbreak seem to be underestimated for 3 weeks after the PHEIC. Was the market's response to the PHEIC rational?

In theory, we should have switched from the initial scenarios/regimes where the likelihood of COVID-19 spreading was little to zero, Figure 1(a), to the second evaluation procedure, Figure 1(b), in which the likelihood of a global spread was greater. Up to this date no strict measures had been taken to stem the spread of the virus. Therefore, in the period 30.01.2020-21.02.2020 the EMH does not seem to work. Was the market inefficient because its response was irrational and/or slow? As Thaler mentions in the interview: could the market's behavior be predictable for a rational model?

In the following week (24/2-28/2), the S\&P500 suffered an $11.49 \%$ loss. This was a week in which many stock markets suffered significant losses ${ }^{17}$. In the U.S., some significant news explains the sharp market decline:

- 24.02: the request for $\$ 2.5$ billion supplementary funds

- 25.02: the C.D.C. Warn of Coronavirus Outbreaks in the U.S. ${ }^{18}$

- 26.02: the CDC report the first case of community spread. Community spread means spread of an illness for which the source of infection is unknown.

Up to 28.02.2020, there were only 63 confirmed COVID-19 cases and no deaths ${ }^{19}$, but the market seems to discount an upcoming health and economic crisis: prices fall $17.87 \%$, and the standard deviation increases to $3.89 \%$ during the $24 / 2-10 / 3$ period. The stock market sooner or later incorporates the COVID-19 risk and its economic consequences in the stock prices ${ }^{20}$. The questions that emerge are the following:

- the PHEIC was an official health alarm; why was the pandemic risk not incorporated (or significantly underestimated) up to 21.02 .2020 ?,

\footnotetext{
${ }^{17}$ During this week the major European stock markets presented sharp declines. This is the week after the report by the Italian authorities regarding clustered COVID-19 cases in Northern Italy: https://www.ecdc.europa.eu/en/publications-data/outbreak-novel-coronavirus-disease-2019-covid-19-situationitaly

${ }^{18}$ https://www.nytimes.com/2020/02/25/health/coronavirus-us.html

${ }^{19}$ First death in the US was reported on 29 February

(https://www.worldometers.info/coronavirus/country/us/)

${ }^{20}$ And this is rational. Even if the market tried to avoid incorporating the health risk, it would eventually incorporate it when COVID-19 cases start to rise and the deaths are documented.
} 
- could an asset pricing model forecast if there will be a slow response by the investors? and

- could a rational model predict exactly when the prices will start to incorporate the news?

If we accept a delay in incorporating COVID-19 risk in market prices, we conclude that the market is not efficient, because it does not always incorporate all the available information at any point in time.

\section{(c) The 11.03.2020-30.04.2020 period.}

During the third period (the post-pandemic declaration period), the stock market gains $1.05 \%$ and the standard deviation is $4.57 \%$. The pandemic declaration, as well as the increased COVID-19 cases and deaths due to the pandemic, in theory should further increase the health risk and lead to further decline in the stock market and an increase in volatility. Does the $1.05 \%$ performance mean that the stock market had instantly and rationally evaluated the ramifications of the pandemic before its declaration? If we examine the sub-period as one period, this could be an explanation, however, similar to the second period, the third period should also be divided in two sub-periods:

- a recession period 11.03.2020 - 23.03.2020, during which the stock market presents $22.37 \%$ losses, and $6.85 \%$ standard deviation, and

- a rocket growth period 24.03.2020-30.04.2020, during which the stock market presents $30.17 \%$ growth, and $3.21 \%$ standard deviation.

Is the sharp decline (ir)rational? Is the rocket growth (ir)rational? Both? Neither? Let's see some of the news during the post-pandemic declaration period. During the sub-period of the sharp decline, there are reports of increased health risk and economic slowdown:

- cancelation and suspension of sport events (12/3),

- on 13.03.2020 the United States Department of Health and Human Services (HHS) reports amongst other that if no measures take place ${ }^{21}$ :

- "A pandemic will last 18 months or longer and could include multiple waves of illness",

- "Increasing COVID -19 suspected or confirmed cases in the U.S. will result in increased hospitalizations among at-risk individuals, straining the healthcare system", and

○ "Supply chain and transportation impacts due to ongoing COVID - 19 outbreak will likely result in significant shortages for government, private sector, and individual U.S. consumers."

- on 15.03.2020 CDC recommends against any gathering of 50 or more people for an eight-week period,

- on 16.03.2020 Imperial College projects 2.2 million deaths in the U.S., and on the same day President Trump halts social activities for groups larger than 10 people, and

- on 17.03.2020 the New York Times revealed the HHS report.

${ }^{21}$ However, this report was unclassified but not for public distribution, therefore on 13.03.2020 the report was not released to the public. 
Most of the aforementioned news is not good and therefore the sharp decline in the market shows that the previous sharp decline during the second period was not an ex-ante discount for an upcoming pandemic declaration, and the $22.37 \%$ loss during the first post pandemic period is proof. The $22.37 \%$ decline is explained by the fact that the news is bad during the 11.03.2020-23.03.2020 period, and generates negative scenarios which are more likely to materialize (as we explained using Figure 1).

During the growth period 24.03.2020-30.04.2020, market growth is $30.17 \%$, most trading days are profitable and, in some days, significantly profitable $(9.38 \%, 7.03 \%, 6.24 \% \ldots)$. The environment, if we focus only on the returns, shows that the pandemic is over, but this does not reflect what is happening in real life: people are still dying from COVID-19, an increased number of cases have been documented during this period, and there is no vaccine. What was the news that has led to the $30.17 \%$ growth?

The boost was given on 24.03 .2020 by the $\$ 2$ trillion stimulus pack which will be given in order to save the national economy. Definitely, this is the new information that stopped the stock market decline, and boosted recovery. Few days later, on Sunday 29, March, Dr. Anthony Fauci, director of the National Institute of Allergy and Infectious Diseases, said that maybe more than 100,000 Americans could die of COVID-19, and that the US is going to have "millions of cases". Does this statement include any good news? It may sound weird, but "yes"; if the stock market had previously taken a much higher death toll as given, e.g. 2.2 million, a projection of 100,000 deaths is still horrifying yet significantly lower than 2.2 million. Therefore, using again the procedure of Figure 1, the previous scenario (2.2 million deaths) overestimated the health risk, and the new scenario for a lower death toll is a reason for the increase in asset prices (upward revision). Similarly, on 09.04.2020, the new estimation of 60k deaths due to COVID-19 is a positive piece of information. Table 2 presents the third period timeline, and the sources $^{22}$.

There are some interesting results in the third period. The increased standard deviations when there is sharp decline are consistent with the leverage effect, but the high volatility during the $30.17 \%$ rocket growth period may hide a disagreement regarding the fair value of the prices (the standard deviation during this period is $3.21 \%$, when during the $02.01 .2020-29.01 .2020$ period a $1.32 \%$ growth is combined with a $0.66 \%$ standard deviation). As it has been mentioned, a behavioral explanation for the high volatility periods may be linked to the overreaction issue (De Bondt and Thaler (1985)) ${ }^{23}$. However, the EMH school of thought may also have another explanation, because the $\$ 2$ trillion stimulus pack may generate controversial results. It may be a positive measure for the reduction of the economic impact of the pandemic, but it may lead to an inflation regime which presents counterarguments regarding its influence on the asset prices:

22 We should note that there could be timelines that may be more detailed e.g. https://www.defense.gov/Explore/Spotlight/Coronavirus/DOD-Response-Timeline/. We present some basic information that serves our paper's scope: to explain how the markets work, and how the news is incorporated to the stock market values.

${ }^{23}$ This is a plausible explanation when examining increased volatility periods during which a lot of news comes to light. 
EVANGELOS Efficient Markets Hypothesis and COVID-19

Table 2: The Basic News During the Post-Pandemic Period.

\begin{tabular}{|c|c|}
\hline Trading Date & Events \\
\hline $11 / 3 / 2020$ & $\begin{array}{l}\text { Pandemic Declaration } \\
\text { https://www.who.int/westernpacific/emergencies/covid-19 }\end{array}$ \\
\hline $12 / 3 / 2020$ & $\begin{array}{l}\text { Nearly every major sporting event in the United States is suspended or canceled } \\
\text { https://www.nytimes.com/2020/03/12/sports/coronavirus-sports-canceled.html }\end{array}$ \\
\hline $13 / 3 / 2020$ & $\begin{array}{l}\text { The United States Department of Health and Human Services (HHS) reports that: "They are necessary } \\
\text { to facilitate planning development efforts.", otherwise } \\
\text { - "A pandemic will last } 18 \text { months or longer and could include multiple waves of illness", } \\
\text { - "Increasing COVID }-19 \text { suspected or confirmed cases in the U .S. will result in increased } \\
\text { Hospitalizations among at-risk individuals, straining the healthcare system", and } \\
\text { - "Supply chain and transportation impacts due to ongoing COVID - } 19 \text { outbreak will likely } \\
\text { result in significant shortages for government, private sector, and individual U. S. } \\
\text { consumers." } \\
\text { We must note that the specific report was marked as unclassified. } \\
\text { https://int.nyt.com/data/documenthelper/6819-covid-19-response- } \\
\text { plan/d367f758bec47cad361f/optimized/full.pdf\#page=1 }\end{array}$ \\
\hline $16 / 3 / 2020$ & $\begin{array}{l}\text { 1. CDC recommends against any gathering of } 50 \text { or more people for an eight-week period }(15 / 3) \\
\text { https://www.cdc.gov/coronavirus/2019-ncov/community/large-events/mass-gatherings-ready-for- } \\
\text { covid-19.html } \\
\text { 2. Imperial Report 9: prediction for } 2.2 \text { million deaths in the U.S. } \\
\text { https://www.imperial.ac.uk/media/imperial-college/medicine/mrc-gida/2020-03-16-COVID19- } \\
\text { Report-9.pdf } \\
\text { 3. U.S. President Donald Trump urges to avoid social gatherings in groups larger than } 10 \text { people. } \\
\text { https://www.reuters.com/article/us-health-coronavirus-usa-guidelines/trump-urges-us-to-halt-most- } \\
\text { social-activity-in-virus-fight-warns-of-recession-idUSKBN2133GT }\end{array}$ \\
\hline $17 / 3 / 2020$ & $\begin{array}{l}\text { The HHS report goes to public. } \\
\text { https://www.nytimes.com/2020/03/17/us/politics/trump-coronavirus-plan.html }\end{array}$ \\
\hline $24 / 3 / 2020$ & $\begin{array}{l}\text { Rumors regarding a } \$ 2 \text { trillion stimulus pack. } \\
\text { https://abcnews.go.com/Business/futures-us-financial-markets-spike-overnight-hit- } \\
\text { limit/story?id=69765921 }\end{array}$ \\
\hline $30 / 3 / 2020$ & $\begin{array}{l}\text { Dr. Anthony Fauci, director of the National Institute of Allergy and Infectious Diseases, said on } \\
\text { Sunday 29, March that maybe more than 100,000 Americans could die of COVID-19, and that the US } \\
\text { is going to have "millions of cases". } \\
\text { https://edition.cnn.com/2020/03/29/politics/coronavirus-deaths-cases-anthony-fauci- } \\
\text { cnntv/index.html }\end{array}$ \\
\hline 9/4/2020 & $\begin{array}{l}\text { Dr. Fauci said that "The final toll currently "looks more like } 60,000 \text { than the } 100,000 \text { to } 200,000 \text { " that } \\
\text { U.S. officials previously estimated. } \\
\text { https://www.npr.org/2020/04/09/830664814/fauci-says-u-s-coronavirus-deaths-may-be-more-like- } \\
\text { 60-000-antibody-tests-on-way }\end{array}$ \\
\hline
\end{tabular}

- Fama and Schwert (1977) show negative results in stock markets prices and inflation, while

- Boudoukh and Richardson (1993) argue that there is "a positive relation between nominal stock returns and inflation at long horizons" because the income generated by real assets should be a hedge against inflation. 
Which explanation describes rational/irrational behavior? In theory, both explanations are correct. However, is it easy to ex-ante predict if the stock market will adopt the short-term or the long-term inflation scenario?

Moreover, even if we accept that the stimulus pack is a strong factor that turns the financial trend from negative to positive: is the $30.17 \%$ growth rational when COVID-19 still threaten the U.S. and the entire world? The stock market presented a slow response when the news where negative (e.g. PHEIC), however the positive influence of the economic relief programs seems to be instantly incorporated in the stock prices even though the health risk still exists. Therefore, is the market's response always predictable for a rational model or not?

\section{Statistical Evidence Regarding Market Efficiency.}

In this section, we present some statistical evidence that quantitatively confirms what we previously mentioned: that the stock market during the examined period was not efficient. At this point, we should note that the main objective of this study is not to present that the stock market is not efficient using econometric methods; however, some quantitative evidence is necessary.

The EMH is based on the random walk hypothesis, according to which the future price is no more predictable than the path of accumulated random numbers. This means that the stock market instantly incorporates all the available information, thus future prices are influenced only by the news that is released. Therefore, an investor cannot use past prices of a certain asset to predict its future prices (Khan \& Vieito (2012)).

Before the efficiency tests, we examine the descriptive statistics of our sample. Table 3 presents the descriptive statistics, which show that the data during the examined period 02.01.2020-30.04.2020 are not normally distributed:

Table 3: Descriptive Statistics of the S\&P500 Daily Returns During the Period 02.01-30.04.2020.

\begin{tabular}{|l||c|}
\hline \multicolumn{2}{|c|}{ S\&P Descriptive Statistics } \\
\hline Mean & $-0.068 \%$ \\
\hline Median & $0.029 \%$ \\
\hline Maximum & $9.383 \%$ \\
\hline Minimum & $-11.984 \%$ \\
\hline Std. Dev. & $3.374 \%$ \\
\hline Skewness & -0.219 \\
\hline Kurtosis & 5.475 \\
\hline Jarque-Bera & $21.847 *$ \\
\hline
\end{tabular}

Note: * indicates statistical significance at $1 \%$ confidence level.

Kurtosis $=5.475>3$, Skewness: $-0.219 \neq 0$, and Jarque-Bera: 21.847 (statistically significant at the $1 \%$ confidence level). Figure 3 shows the non-normality of the distribution graphically. 
EVANGELOS Efficient Markets Hypothesis and COVID-19

Figure 3: Histogram of the S\&P500 Daily Returns During the COVID-19 Outbreak Period (02.01.2020-30.04.2020).

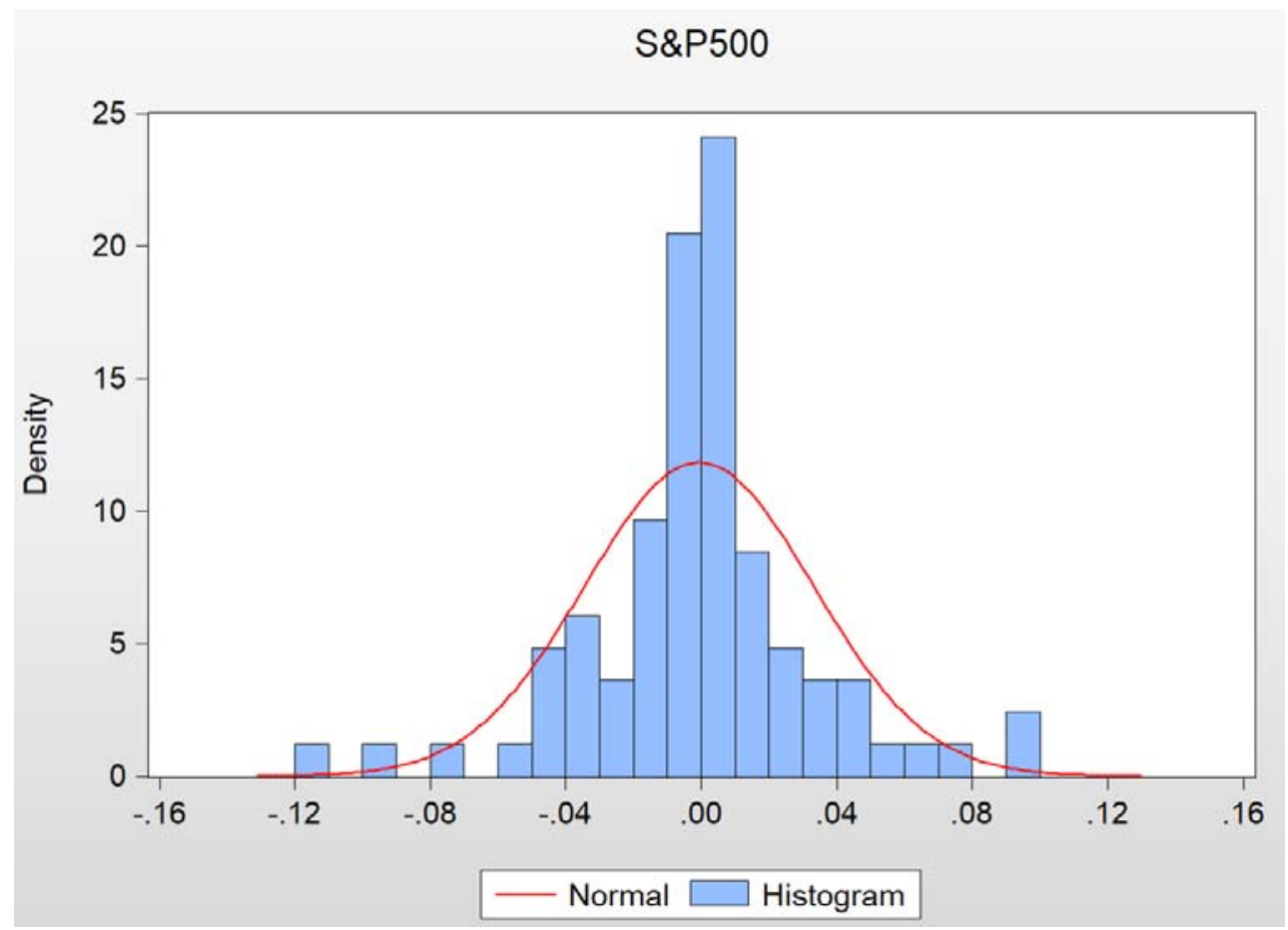

There are several tests that are presented in the financial literature that are used in order to examine the EMH. Khan \& Vieito (2012) examine market efficiency using serial correlation test (ACF test), runs test, unit root test (Kwiatkowski, Philips, Schmidt, \& Shin, 1992), multiple variance ratio test (Chow \& Denning, 1993), and the non-parametric variance ratio test using ranks and signs (Wright, 2000). In our study, the sample is not large, therefore, amongst several popular tests the runs-test, which is appropriate for small samples, seems to be the most appropriate choice for testing the EMH in our sample (Islam, Watanapalachaikul, \& Clark (2007)).

If the markets are efficient, the sample distribution has random returns (positive and negative). As a run we define the repeated consequence of positive (or negative) returns. Some authors adopt a slightly different approach: instead of the positive (negative) returns, they examine the consequence of returns that are above (below) the mean return of the sample, and or the median. In this section, we adopt all these versions of the runs-test using as classification criterion: the zero, the average, and the median value.

The mean return $(\mu)$ of the expected runs is given by the formula

$$
\mu=\frac{2 \times N_{p} \times N_{n}}{N}+1
$$


and the standard deviation $(\sigma)$ by the formula

$$
\sigma=\sqrt{\frac{2 \times N_{p} \times N_{n} \times\left(2 \times N_{p} \times N_{n}-N\right)}{N^{2} \times(N-1)}}=\sqrt{\frac{(\mu-1) \times(\mu-2)}{N-1}}
$$

where $\mathrm{N}_{\mathrm{p}}=$ number of positive observations, $\mathrm{N}_{n}=$ number of negative observations, and $\mathrm{N}=\mathrm{N}_{\mathrm{p}}+\mathrm{N}_{\mathrm{n}}$ the total number of observations. Therefore, the Z-statistic is

$$
Z=\frac{U-\mu}{\sigma}
$$

where $\mathrm{U}=$ the number of runs.

Table 4 shows the results which indicate that the daily returns of our sample are not randomly distributed, either we adopt as classification criterion the zero-return criterion (Daily Return $<>0$ ) or the average-return (Daily Return $<>$ mean return) or the median return (Daily Return $<>$ median return). The p-values show that we should reject the randomness hypothesis at the $1 \%, 5 \%$ and $1 \%$ confidence level, respectively. This is a quantitative indication that the U.S. stock market is not efficient during the examined period.

Table 4: Run-tests for the S\&P500 Daily Returns during the 02.01.2020-30.04.2020 Period.

\begin{tabular}{|l||c|l|l|l|l|l|l|}
\hline $\begin{array}{l}\text { Criterion for } \\
\text { Positive/Negative } \\
\text { Classification }\end{array}$ & $\begin{array}{l}\text { Number } \\
\text { of Runs }\end{array}$ & $\begin{array}{l}\text { Expected } \\
\text { Mean } \\
\text { Number } \\
\text { of Runs }\end{array}$ & $\begin{array}{l}\text { Expected } \\
\text { Standard } \\
\text { Deviation } \\
\text { Number of } \\
\text { Runs }\end{array}$ & $\begin{array}{l}\text { Number of } \\
\text { Positive } \\
\text { Observations } \\
\left(\mathrm{N}_{\text {positive }}\right)\end{array}$ & $\begin{array}{l}\text { Number of } \\
\text { Negative } \\
\text { Observations } \\
\left(\mathrm{N}_{\text {negative }}\right)\end{array}$ & $\begin{array}{l}\text { Runs } \\
\text { Test } \\
\text { Value } \\
(Z)\end{array}$ & $p$-value \\
\hline \hline $\begin{array}{l}\text { Daily Return }<>0 \\
\text { Daily Return }<> \\
\text { mean return } \\
(-0.068 \%)\end{array}$ & 56 & 42.494 & 4.527 & 42 & 41 & 2.984 & $0.0028^{*}$ \\
\hline $\begin{array}{l}\text { Daily Return }<> \\
\text { median return } \\
(0.029 \%)\end{array}$ & 56 & 42.446 & 4.521 & 43 & 40 & 2.555 & $0.0106^{* *}$ \\
\hline
\end{tabular}

Note: $*$ and $* *$ indicate statistical significance at $1 \%, 5 \%$ confidence level, respectively.

\section{Conclusions}

This paper tries to present in a simple way the behavior of the US stock market during the COVID-19 outbreak period. The data and the released news show that the US stock market seems not always efficient during the COVID-19 outbreak period.

In January and up to the PHEIC announcement, the stock market is positive $1.32 \%$ and with low standard deviation $0.66 \%$. Even though the authorities did not give worrying messages regarding the 
COVID-19 outbreak in the US, was it rational to assume that an easily spread virus would not affect a country such as the U.S. with metropolitan centers and millions of travelers visiting from all around the globe? In our opinion, the indicator on which we should focus is standard deviation because the low standard deviation shows that the market does not have counterarguments regarding the 31.12.201929.01.2020 positive returns. That means that no scenario where COVID-19 becomes a global threat was taken into serious consideration.

A financial analyst/supporter of the EMH may suggest that up to the PHEIC no official worrying declaration was made and so the markets reacted accordingly. Can we say the same for the period after the PHEIC announcement? The stock market's performance during the first days after the PHEIC (up to 21.02.2020) does not show any cause for concern: positive returns and slightly increased standard deviation relative to the pre-PHEIC period, which means that the US stock market was not alarmed by the PHEIC. WHO sounded the alarm, PHEIC, over a global outbreak of the virus. As a consequence, the PHEIC should lead to market decline due to an economic slowdown and due to increased risk aversion, but the market did not respond instantly, and rationally during this period. Was this response predictable? Our concerns are not only the positive returns from PHEIC announcement up to 21.02.2020, but once again the low standard deviations. Did all the market participants underestimate the PHEIC announcement, or was there overoptimism on the part of many investors, so the pandemic risk was absorbed?

The market seems to incorporate the news regarding the COVID-19 outbreak after 24.02.2020 and up to the end of the second period (10.03.2020); therefore, we could assume that finally the stock market incorporated the health risk. An EMH supporter may suggest that this is a slow response. However, the slow response means that in some periods the stock market does not incorporate the available information. As Thaler mentions ${ }^{24}$, this is an issue on which further research should be done regarding the behavioral factor that could be added in an asset pricing model in order to turn a rational model into an efficient one.

The $22.37 \%$ decline during the $11.03 .2020-23.03 .2020$ period and the $30.17 \%$ growth during the 24.03.2020 -17.04.2020 period seem to instantly incorporate the negative news regarding the pandemic and the positive information regarding the economic relief programs, respectively. The increased standard deviations during the decline period are consistent with the leverage effect, but the volatility is high for a $30.17 \%$ rocket growth period. The latter may hide a disagreement regarding the fair value of the prices. For example, some investors may focus only on the positive influence by the relief programs and underestimate the fact that COVID-19 is still causing the death of thousands of people worldwide and in the U.S. On the other hand, other investors may not be so optimistic and take the pandemic scenario into account.

The market's controversial perceptions regarding the influence of the $\$ 2$ trillion stimulus pack may be another explanation, e.g. relief programs may be a positive measure for the reduction of the economic

\footnotetext{
${ }^{24}$ The interview is available on https://www.youtube.com/watch? $\mathrm{v}=\mathrm{bM} 9 \mathrm{bYOBuKF} 4 \& \mathrm{t}=1799 \mathrm{~s}$, and the part we
} mentioned is on 28:39-28:53. 
impact of the pandemic, but it may lead to an inflation regime which influences the stock market prices either negatively (Fama and Schwert (1977)) or positively at long periods (Boudoukh and Richardson (1993)). What is the rational response to the inflation regime?

We mentioned many times that the stock market was not efficient during the examined period, examining only the market's performance and the released news. Taking into consideration the properties of our sample, we used the runs-test which rejects the random walk hypothesis and provides statistical evidence that the U.S. stock market during the COVID-19 pandemic was not efficient.

Finally, we should highlight the fact the econometric tests for the EMH are heavily based on randomness, and this could be a topic for future research. If we assume that the runs tests indicate that returns are random during the last rocket growth period, does it mean that the market is efficient? Shares started rising in the US because of the announcement of the stimulus pack, but is a $30.17 \%$ growth rational? Randomness does not mean rationality; therefore, this crisis may give financial economist the chance to examine market efficiency under new circumstances.

\section{References}

Al-Awadhi, A. M., Al-Saifi, K., Al-Awadhi, A., \& Alhamadi, S. (2020), Death and contagious infectious diseases: Impact of the COVID-19 virus on stock market returns, Journal of Behavioral and Experimental Finance, 27, 100326.

Almond, D., \& Mazumder, B. (2005), The 1918 influenza pandemic and subsequent health outcomes: an analysis of SIPP data, American Economic Review, 95(2), 258-262.

Boudoukh, J., \& Richardson, M. (1993), Stock returns and inflation: A long-horizon perspective, American Economic Review, 83(5), 1346-1355.

Chow, K., \& Denning, K. (1993), A simple multiple variance ratio test, Journal of Econometrics, 58, 385-401.

Cohn, A., Engelmann, J., Fehr, E., Maréchal, M.A., (2015), Evidence for countercyclical risk aversion: an experiment with financial professionals, American Economic Review, 105 (2), 860-885.

De Bondt, W. F., \& Thaler, R. (1985), Does the stock market overreact?, Journal of Finance, 40(3), 793-805.

Decker, S., \& Schmitz, H. (2016), Health shocks and risk aversion, Journal of Health Economics, 50, 156-170.

Fama, E. F. (1970), Efficient capital markets: A review of theory and empirical work, Journal of Finance, 25(2), 383-417.

Fama, E. F., \& French, K. R. (1988), Dividend yields and expected stock returns, Journal of Financial Economics, 22(1), 3-25.

Fama, E. F., \& Schwert, G. W. (1977), Asset returns and inflation, Journal of Financial Economics, $5(2), 115-146$.

Garrett, T. A. (2008), Pandemic economics: The 1918 influenza and its modern-day implications, Federal Reserve Bank of St. Louis Review, 90(March/April 2008). 
Islam, S. M., Watanapalachaikul, S., \& Clark, C. (2007), Some tests of the efficiency of the emerging financial markets: An analysis of the Thai stock market, Journal of Emerging Market Finance, 6(3), 291-302.

Kwiatkowski, D., Phillips, P. C., Schmidt, P., \& Shin, Y. (1992), Testing the null hypothesis of stationarity against the alternative of a unit root, Journal of Econometrics, 54(1-3), 159-178.

Keogh-Brown, M. R., Wren-Lewis, S., Edmunds, W. J., Beutels, P., \& Smith, R. D. (2010), The possible macroeconomic impact on the UK of an influenza pandemic, Health Economics, 19(11), 1345-1360.

Khan, W., \& Vieito, J. P. (2012), Stock exchange mergers and weak form of market efficiency: The case of Euronext Lisbon, International Review of Economics \& Finance, 22(1), 173-189.

Malmendier, U., Nagel, S., (2011), Depression babies: do macroeconomic experiences affect risk taking?, Quarterly Journal of Economics 126 (1), 373-416.

Shiller, R. J. (1981), Do Stock Prices Move Too Much to be Justified by Subsequent Changes in Dividends?, American Economic Review, 71(3), 421-436.

Wright, J. (2000), Alternative variance-ratio tests using ranks and signs, Journal of Business and Economic Statistics, 18(1), 1-9. 

Review of Economic Analysis 13 (2021) 45-62 3909/2021045

1973- 